\title{
Implementing an epilepsy surgery center. Initial experience at a university hospital in Brazil
}

\author{
Implementação de um centro de cirurgia de epilepsia. Experiência inicial \\ em um hospital universitário no Brasil \\ Gabriel Pereira Escudeiro', Rafael Teixeira Magalhães Leal', Heros Henrique Melo de Almeida', \\ Marcus Andre Acioly', José Alberto Landeiro', Bruno Lima Pessoa ${ }^{1}$
}

\begin{abstract}
Epilepsy is a serious neurological condition, often without a full and effective treatment. In some cases, surgery is beneficial, despite being underused. Our aim herein is to describe the implementation of an epilepsy surgery center in a federal university hospital, sharing the initial experience gained, as well as describing the main challenges and first results. Methods: Experience report of an epilepsy surgery center implementation. Retrospective review of 13 drug-resistant patients who underwent surgical treatment. Results: Thirteen patients underwent surgical epilepsy treatment, five patients categorized as the International League Against Epilepsy class 1, two in class 2, three in class 3, zero in class 4, and two in class 5; with a $30.76 \%$ complication rate. Conclusion: Despite the challenges, it was possible to implement an epilepsy surgery center with favorable results and acceptable incidence of complications, which were not higher than the incidences found in more experienced centers.
\end{abstract}

Keywords:epilepsy; neurocirurgical procedures; developing countries.

\section{RESUMO}

Epilepsia é um problema neurológico sério e para o qual não há um tratamento efetivo e definitivo. Apesar de o tratamento cirúrgico ser bastante benéfico em alguns casos, ainda é subutilizado. O objetivo deste trabalho é descrever a implementação de um Centro de Cirurgia de Epilepsia em um Hospital Universitário Federal, divulgar a experiência inicial obtida, os principais desafios, as dificuldades e os resultados iniciais. Método: Relato da experiência na implementação do Centro de Epilepsia. Análise retrospectiva de série de treze pacientes com epilepsia resistente a medicação e que foram submetidos a tratamento cirúrgico. Resultados: Treze pacientes submetidos a tratamento cirúrgico, 5 com a Liga Internacional Contra Epilepsia classe 1, 2 com classe 3, três com classe 3, zero com classe 4 e 2 com classe 5; com uma taxa de complicação de 30, 76\%. Conclusão: Apesar das dificuldades, foi possível a implementação de um Centro de Cirurgia de Epilepsia com resultados favoráveis e taxas de complicação não superiores aos centros de países desenvolvidos.

Palavras-chave: epilepsia; procedimentos neurocirúrgicos; países em desenvolvimento

Epilepsy is a serious neurological condition, which is often neglected as a major public health problem ${ }^{1}$. It was first described approximately 4,000 years ago. Throughout history, it has been considered a contagious disease, or witchcraft, with a demonic or spiritual etiology, for which many treatments have been proposed ${ }^{2,3}$. Since then, our knowledge regarding epilepsy has greatly increased. Numerous studies have been conducted and novel treatments have been suggested. However, even today, our knowledge remains limited and there is no fully effective treatment for this condition ${ }^{2,3}$.

Several diagnostic criteria have been indicated for refractory epilepsy. Juul-Jensen defined as refractory seizures those that failed with at least two first-line drugs ${ }^{4}$. Further, Gilman et al. characterized as refractory seizures those in which the first-line anticonvulsant drugs were attempted in their usual doses but did not yield the desired response ${ }^{5}$. The International League Against Epilepsy (ILAE) defines the term "drug resistant epilepsy" as "failure of adequate trials of two tolerated and appropriately chosen and used anti-epileptic drug schedules (whether as monotherapies or in combination) to achieve sustained seizure freedom"6.

Approximately $1 \%$ of the world's population is affected by epilepsy ${ }^{1}$. Unfortunately, there are very few studies regarding the prevalence and incidence of epilepsy in Brazil. It is

${ }^{1}$ Hospital Universitário Antônio Pedro, Niterói RJ, Brasil.

Correspondence: Gabriel Pereira Escudeiro; Rua Marques do Paraná, 303 / prédio principal / $3^{\circ}$ andar; 24033-900 Niterói RJ, Brasil;

E-mail: gabrielescudeiro@yahoo.com.br

Conflict of interest: There is no conflict of interest to declare.

Support: This project had FAPERJ's (Fundação de Amparo à Pesquisa do Estado do Rio de Janeiro) incentives..", register: E-26/110.245/2014

Received 31 May 2017; Received in final form 07 July 2017; Accepted 17 July 2017. 
estimated that there were 340,000 new epilepsy cases in 2005 and the prevalence reached 1.8 million patients in the country the same year ${ }^{7}$. Depending upon the criteria used, $9 \%$ to $24 \%$ of the patients are considered inadequately controlled with antiepileptic drugs ${ }^{8}$.

In 1828, Benjamin Dudley reported on one of the first epilepsy surgeries, conducted on a patient who developed seizures after brain trauma. The surgery consisted of decompressive trepanation, and a good result was obtained ${ }^{9}$. In 1886, Sir Victor Horsley, guided by Hughlings Jackson, performed surgery on a 22-year-old man with a long-term epilepsy after an accident resulting in a depressed skull fracture. Horsley found an area of brain scarring, which was resected with a $0.5 \mathrm{~cm}$ margin and the patient became seizure free ${ }^{10}$. Since then, knowledge regarding epilepsy surgery has increased with contributions from many famous surgeons, highlighted by Fedor Krause, Harvey Cushing, Otfrid Foerster, Wilder Penfield, Herbert Jasper and Paulo Niemeyer ${ }^{11}$.

Through the years, both pathophysiology and surgical techniques for this disease have greatly improved. Epilepsy surgery has become more effective, especially in patients with mesial temporal atrophy and extratemporal lesions ${ }^{12}$. A Cochrane Library meta-analysis found that the group of patients who underwent surgery was 15 times more likely to become seizure free compared with exclusive clinical treatment ${ }^{13}$.

Our aim is to describe the implementation of an epilepsy surgery center at a university hospital in the southeastern region of Brazil. By sharing our initial experience and describing the main challenges found, we hope to stimulate the implementation of new epilepsy surgery centers. In addition, we present the results of a series of patients treated with epilepsy surgery at our institution.

Box 1. Engel surgical outcome classification.

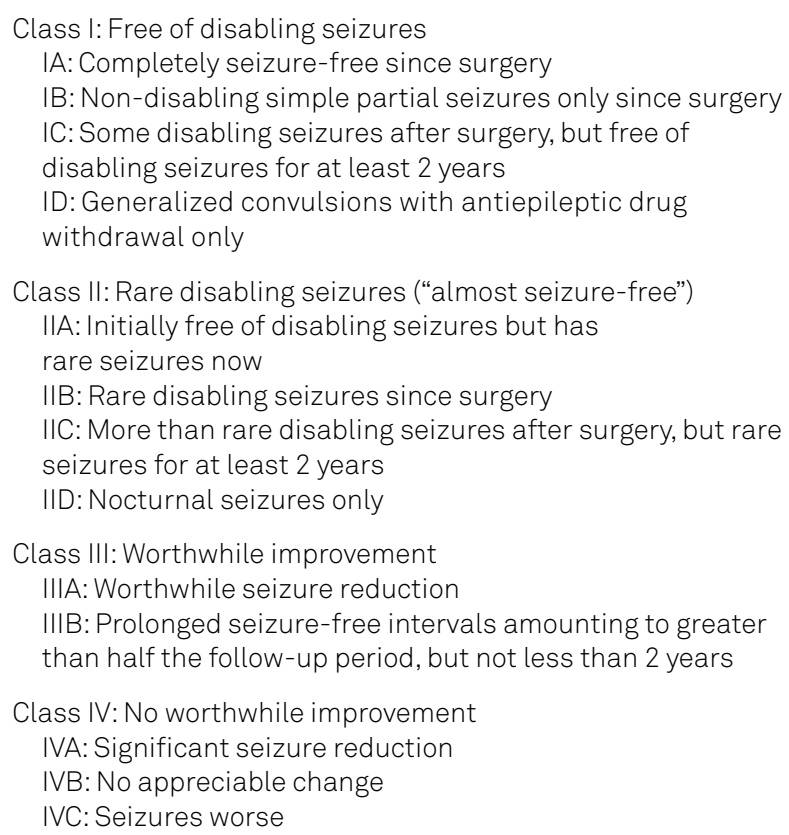

\section{METHODS}

We reviewed all charts of patients with medically-resistant seizures who underwent a surgical treatment from September 2012 to April 2016. The diagnostic criteria used were those proposed by the ILAE, as previously mentioned.

Regarding the surgical technique, all patients underwent a neuronavigation-based craniotomy. Non-selective amydalohippocampectomy (NSAH), Spencer's technique, was performed for mesial temporal sclerosis, with or without associated tumor. In patients with tumor-associated epilepsy in the mesial portion of temporal lobe, standard tumor resection was performed, associated with NSAH. Lateral temporal lobe tumors and extratemporal ones were treated with tumor resection by standard neurosurgical technique.

All information was obtained from our registry platform (electronic chart). The outcomes of interest were the Engel Classifications after surgery ${ }^{14}$ (Box 1) and the ILAE scores ${ }^{15}$ (Box 2). Both complications and clinical outcomes were registered.

\section{RESULTS}

From September 2012 to April 2016, 13 patients met the inclusion criteria. Eight men and five women were included. The mean age was 33 years old ( 17 to 57 years), and the follow-up was seven to 43 months, excluding one case of death in the postoperative period. All but one patient had temporal lobe epilepsy, MRI positive findings and concordant EEG.

Demographic data such as age, gender, etiology, laterality, type of surgery and outcome scores are shown in the Table. According to the Engel outcome classification, there were five patients classified as IA, 3 as IB, one IC, one IIC, one IIIB, and one IVB; there were no patients in the other categories (Figure 1). According to the ILAE outcome scale, five patients were class 1 , two class 2 , three class 3 , and two class 5 (Figure 2).

Of the 13 patients who underwent surgery, four (31\%) had some sort of complication. One ( $8 \%$ ) patient developed a temporal bleed immediately after surgery, which was promptly drained, but this patient eventually died due to pulmonary sepsis. Only one patient ( $8 \%$ ) developed symptomatic quadrantanopia, confirmed by complementary examinations. Two (16\%) developed a psychiatric disorder; one characterized by childish behavior

Box 2. International League Against Epilepsy outcome scale.

Class 1: Completely seizure free; no auras

Class 2: Only auras; no other seizures

Class 3: 1 to 3 seizure days per year; \pm auras

Class $4: 4$ seizure days per year to $50 \%$ reduction of baseline

seizure days; \pm auras

Class 5: Less than $50 \%$ reduction of baseline seizure days; \pm auras

Class 6: More than $100 \%$ increase of baseline seizure days; \pm auras 
Table.Demographic data of age, gender, etiology, laterality, type of surgery and outcome scores.

\begin{tabular}{|c|c|c|c|c|c|c|}
\hline Gender & Age & Alteration & Side & Procedure & ILAE & Engel \\
\hline Male & 53 & Hippocampal atrophy & Right & $\mathrm{NSAH}$ & 2 & IB \\
\hline Male & 17 & Temporal mesial tumor & Right & Resection + NSAH & 1 & IA \\
\hline Female & 49 & Hippocampal atrophy and DNET & Right & Resection + NSAH & 3 & IB \\
\hline Male & 40 & Neocortical temporal-occipital tumor & Right & SR & 2 & IB \\
\hline Female & 16 & Temporal mesial tumor & Right & Resection + NSAH & 1 & IA \\
\hline Female & 25 & Frontal cavernoma & Right & SR & 1 & IA \\
\hline Male & 39 & Hippocampal atrophy & Right & $\mathrm{NSAH}$ & 1 & IA \\
\hline Female & 34 & Hippocampal atrophy & Right & $\mathrm{NSAH}$ & 1 & IA \\
\hline Male & 58 & Hippocampal atrophy & Right & NSAH & 5 & IVB \\
\hline Female & 39 & Hippocampal atrophy & Right & $\mathrm{NSAH}$ & 3 & IC \\
\hline Female & 24 & Hippocampal atrophy & Right & $\mathrm{NSAH}$ & 3 & $\| \mathrm{C}$ \\
\hline Male & 49 & Neocortical temporal tumor & Right & SR & 5 & IIIB \\
\hline
\end{tabular}

SR: Standard resection; NSAH: non-selective amygdalohippocampectomy; DNET: dysembryoplastic neuroepithelial tumour

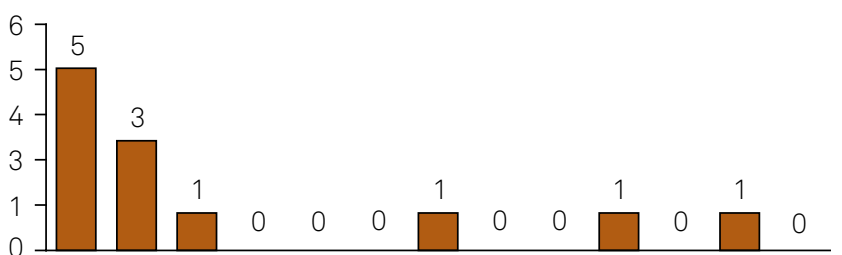

IA IB IC ID $\quad \mid A \quad\|B \quad\| C \quad\|D \quad\| I A \quad \| B \quad I V A \quad I V B \quad I V C$

Figure 1. Engel surgical outcome classification

and visual hallucinations and one developed depression; both were referred for psychiatric and psychological care.

Considering the difficulties found in the implementation process, we highlight the following:

Firstly, because of the under-referral from other physicians, such as neurologists and general physicians from basic health care centers, it became necessary, in some cases, to actively recruit patients. Furthermore, there were not enough hospital beds, especially ones dedicated to epilepsy patients.

Secondly, there was difficulty accessing video EEG. Although EEG video equipment had been obtained through a research project, there was, at the time, no medical room or personnel (medical and non-medical) for its full operation. Moreover, there was neither transoperative stimulation or electrocorticography in our service.

\section{DISCUSSION}

In the United States, in 1987, there were only 26 epilepsy surgery centers. In 1992, this increased to 67 centers $^{16}$. Unfortunately, to the best of our knowledge, there is no such data in Brazil. However, it is well known that the number of centers that offer this type of surgery is not enough to care for this country's population. Thus, the implementation of epilepsy surgery centers is critical.

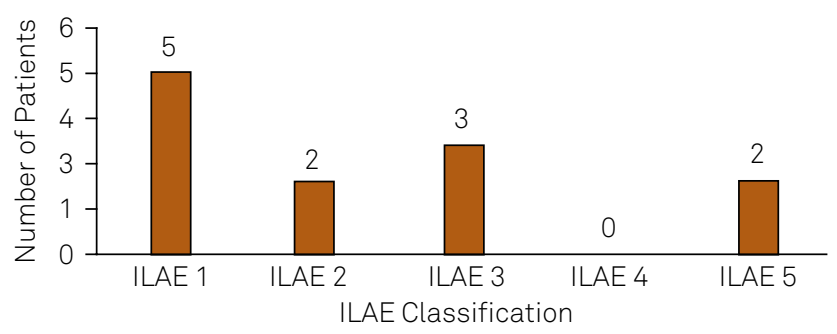

Figure 2. International League Against Epilepsy outcome scale.

Ours is the only public institution with an epilepsy surgery team in a subregion made up by seven cities and a population of $1,857,345^{17}$. It is the referral center for many specialties, including neurosurgery and neurology. When epidemiological data ${ }^{1,8,18}$ is extrapolated to our population, it is estimated that approximately 1,650 to 7,350 refractory epilepsy patients could potentially benefit from surgery, or, at least, a surgical evaluation. However, our sample consisted of only 13 patients, a much lower number compared to the estimated population.

Other authors have reported that, despite the currently available evidence, surgery for refractory epilepsy is underutilized. As Jatté et al. mentioned in their review, that there is a gap between evidence and practice, and that epilepsy surgery is underused in countries such as the USA, UK and Canada. They pointed out some factors that might contribute to the phenomenon: incomplete or biased data, under-referral to surgery centers, access issues, efficacy of new antiepileptic drugs, effectiveness of surgery in children, lack of knowledge and misconceptions, and behavioral or cultural issues ${ }^{12}$.

We had similar problems to those experienced by more economically-developed countries, such as under-referral. However, we also have different problems, more typical of developing countries, such as the lack of supplies and hospital beds. This observation is of utmost importance, since the regional characteristics of the health care system impose different issues for the implementation of an epilepsy center. 
Therefore, we consider the report of the current active epilepsy surgery centers'experiences, as well as the information exchange, to be very important.

Despite the difficulties faced, our patients had good outcomes, as established by the Engel and ILAE classifications, and a relatively low complication rate. De Tisi et al. ${ }^{19}$, in a series of 649 patients undergoing surgical treatment for epilepsy in the UK found that $40 \%$ became entirely seizure free and $11 \%$ improved (simple partial seizure only). Their results were very similar to ours. With respect to complications, they had a $3 \%$ mortality, $8 \%$ visual field defects in temporal lobe epilepsy, $5 \%$ wound infections, $<1 \%$ hemiparesis; $2 \%$ frontalis muscle weakness; $1 \%$ dysphasia; $3 \%$ cerebro spinal fluid leaks needing intervention, and one deep venous thrombosis, with an overall complication rate of $22 \%^{19}$.

In a meta-analysis conducted by Téllez-Zenteno et al. ${ }^{20}$, with data from 76 studies, they found a $66 \%$ seizure-free rate after surgery (Engel I) for temporal lobe epilepsy, including tumor and non-tumor diseases. In this same meta-analysis, they found a $46 \%$ seizure-free rate after occipital and parietal resections and a $27 \%$ seizure-free rate after frontal lobe resections; and $35 \%$ of the patients became free of incapacitating seizures after callosotomy ${ }^{20}$.

Thus, considering that temporal lobe epilepsy has a better outcome after surgical treatment ${ }^{19}$, we decided to select patients with this condition, if possible, for our initial experience.

Psychosocial disabilities are more prevalent in patients with refractory seizures, with lower social interaction and reduced marriage rates ${ }^{21}$. Vickrey et al..$^{22}$ compared the quality of life in patients with epilepsy and other diseases (hypertension, diabetes, heart disease and depression). They concluded that patients who became seizure free after surgery had a better quality of life than the others ${ }^{22}$.
In a review of the causes of epilepsy-related death, Rufo-Campos ${ }^{23}$ listed sudden death, status epilepticus, trauma in general, aspiration pneumonia, drowning and burns. In a study by Ferreira and Silva ${ }^{24}$, the authors conducted a subsystem information survey on mortality in the Ministry of Health between 1980 and 2003 and found 32,655 deaths to bea direct consequence of epilepsy, which was calculated as an average of 1,236 deaths per year. The authors emphasized that these data are probably underestimated due tounder-reporting ${ }^{24}$.

Berg et al. ${ }^{25}$ reported a 20-year delay between the onset of seizures and the referral for surgery evaluation. Sillanpääet al. ${ }^{26}$ performed a long-term follow-up with 220 children diagnosed with epilepsy in Finland. They pointed out that the most important predictor for seizure control was a rapid response to initial therapy, defined as the reduction of seizures- at least $75 \%$ in three months - and when this percentage was not achieved, surgery should be considered.

Considering the lack of a center for epilepsy surgery in our region, we are committed to the implementation of this project. So far, great results have been attained.

We decided to publish our initial results and our major difficulties to encourage other neurosurgical teams, withconditions similar to ours, to implement an epilepsy center.

Epilepsy is a serious health problem and the surgical approach is potentially beneficial for a considerable proportion of patients with this disease, although, in some areasofthe world, the access of these patients to a surgery team is not possible.

In conclusion, we present the implementation of an epilepsy surgery center with favorable results and low incidence of complications (very similar to more developed centers). We believe that, in a region without this resource, neurosurgeons should be encouraged to implement an epilepsy center.

\section{References}

1. Bruce M, Griffiths C, Brock A, Majeed A. Trends in mortality and hospital admissions associated with epilepsy in England and Wales during the 1990s. Health Stat Q. 2004; (21):23-9.

2. Li LM, Sander JW. National demonstration project on epilepsy in Brazil. ArqNeuropsiquiatr, 2003; 61(1):153-6. https://doi.org/10.1590/S0004-282X2003000100033

3. Gomes MM. [History of epilepsy: a epistemologic point of view]. J Epilepsy ClinNeurophysiol. 2006; 12(3):161-7. Portuguese. https://doi.org/10.1590/S1676-26492006000500009

4. Berg AT, Vickrey BG, Langfitt JT, Sperling MR, Walczak TS, Shinnar $S$ et al. The multicenter epilepsy surgery: recruitment and selection for surgery. Epilepsia. 2003; 44(11):1425-33. https://doi.org/10.1046/j.1528-1157.2003.24203.x

5. Gilman JT, Duchowny M, Jayakar P, Resnick TJ. Medical intractability in children evaluated for epilepsy surgery. Neurology. 1994; 44(7):1341-3. https://doi.org/10.1212/WNL.44.7.1341

6. Kwan P, Arzimanoglou A, Berg AT, Brodie MJ, Allen Hauser W, Mathern $G$ et al. Definition of drug resistant epilepsy: consensus proposal by the ad hoc Task Force of the ILAE Commission on Therapeutic Strategies. Epilepsia. 2010; 51(6):1069-77. https://doi.org/10.1111/j.1528-1167.2009.02397.x
Gallucci Neto J, Marchetti LR. [Epidemiologic aspects and relevance of mental disorders associated with epilepsy]. Rev Bras Psiquiatr. 2005; 27(4):323-8. Portuguese. https://doi.org/10.1590/S1516-44462005000400013

8. Berg AT, Kelly MM; Defining intractability: comparisons among published definitions. Epilepsia. 2006; 47(2):431-6. https://doi.org/10.1111/j.1528-1167.2006.00440.x

9. Jensen RL, Stone JL. Benjamin Winslow Dudley and early American trephination for posttraumatic epilepsy. Neurosurgery. 1997; 41(1):263-8. https://doi.org/10.1097/00006123-199707000-00045

10. Sengoku A. The contribution of J. H. Jackson to present-day epileptology. Epilepsia. 2002; 43 Suppl 9:6-8. https://doi.org/10.1046/j.1528-1157.43.s.9.3.x

11. Feindel W. Leblanc R, Almeida AN. Epilepsy surgery: historical highlights 1909-2009. Epilepsia. 2009; 50(Suppl. 3):131-51. https://doi.org/10.1111/j.1528-1167.2009.02043.x

12. Jetté N, Sander JW, Keezer MR. Surgical treatment for epilepsy: the potential gap between evidence and practice. Lancet Neurol. 2016; 15(9):982-94. https://doi.org/10.1016/S1474-4422(16)30127-2 
13. West S, Nolan SJ, Cotton J, Gandhi S, Weston J, Sudan A et al. Surgery for epilepsy (Review). Cochrane Database of Systematic Reviews. 2015; (7):120.

14. Engel J, Cascino GD, Ness PCV, Rasmussen TB, Ojemann LM. Outcome with respect to epileptic seizures. In: Engel J, editor. Surgical treatment of the epilepsies. NY: Raven Press; 1993. p. 609-21.

15. Wieser HG, Blume WT, Fish D, Goldensohn E, Hufnagel A, King D et al. Proposal for a new classification of outcome with respect to epileptic seizures following epilepsy surgery. ILAE Commission Report. Epilepsia. 2001; 42(2):282-6

16. Passaro EA. Identification of potential epilepsy surgery candidates. Medscape. 2014 [cited 2017 Jan 10] Available from: http:// emedicine.medscape.com/article/1185635-overview

17. Instituto Brasileiro de Geografia e Estatística - IBGE. Contagem da População 2007. Rio de Janeiro: Instituto Brasileiro de Geografia e Estatística; 2008. p. 82-3

18. Fernandes J, Schmidt M, Monte T, Tozzi S, Sander J. Prevalence of epilepsy: the Porto Alegre Study. Epilepsia. 1992; 33 Suppl 3:132.

19. Tisi J, Bell GS, Peacock JL, McEvoy AW, Harkness WF, Sander JW et al. The long-term outcome of adult epilepsy surgery, patterns of seizure remission, and relapse: a cohort study. Lancet. 2011;378(9800):1388-95. https://doi.org/10.1016/S0140-6736(11)60890-8
20. Téllez-Zenteno F, Dhar R, Wiebe S. Long-term seizure outcomes following epilepsy surgery: a systematic review and meta-analysis. Brain. 2005; 128:1188-98. https://doi.org/10.1093/brain/awh449

21. Sperling MR. The consequences of uncontrolled epilepsy. CNS Spectr. 2004; 9(2):98-101. https://doi.org/10.1017/S1092852900008464

22. Vickrey BG, Hays RD, Rausch R, Sutherling WW, Engel J Jr, Brook RH. Quality of life of epilepsy surgery patients as compared with outpatients with hypertension, diabetes, heart disease, and/or depressive symptoms. Epilepsia. 1994;35(3):597-607. https://doi.org/10.1111/j.1528-1157.1994.tb02480.x

23. Rufo-Campos M. Mortalidadenlas epilepsias. RevNeurol. 2000;30 Supl1:S110-4.

24. Ferreira ILM, Silva TPT. [Mortality from epilepsy in Brazil, 1980-2003]. CienSaúdeColetiva. 2009; 14(1):89-94. Portuguese. http://dx.doi.org/10.1590/S1413-81232009000100014

25. Berg AT, Langfitt J, Shinnar S, Vickrey BG, Sperling MR, Walczak T et al. How long does it take for partial epilepsy to become intractable? Neurology. 2003;60(2):186-90. https://doi.org/10.1212/01.WNL.0000031792.89992.EC

26. Sillanpää M, Jalava M, Kaleva O, Shinnar S. Long-term prognosis of seizures with onset in childhood. N Engl J Med. 1998; 338(24):1715-22. https://doi.org/10.1056/NEJM199806113382402 


\section{Erratum}

Arq Neuropsiquiatr 2017;75(10):722-726. DOI: http://dx.doi.org/10.1590/0004-282x20170125

\section{The name of the authors:}

Gabriel Pereira Escudeiro ${ }^{1}$, Rafael Teixeira Magalhães Leal ${ }^{1}$, Heros Henrique Melo de Almeida ${ }^{1}$, Marcus Andre Aciolly ${ }^{1}$, José Alberto Landeiro ${ }^{1}$, Bruno Lima Pessoa ${ }^{1}$

\section{Should be:}

Gabriel Pereira Escudeiro ${ }^{1}$, Rafael Teixeira Magalhães Leal ${ }^{1}$, Heros Henrique Melo de Almeida ${ }^{1}$, Marcus Andre Acioly ${ }^{1}$, José Alberto Landeiro ${ }^{1}$, Bruno Lima Pessoa ${ }^{1}$ 